\title{
The Lon protease regulates swarming motility and virulence gene expression in Proteus mirabilis
}

\section{Correspondence \\ Philip N. Rather \\ prather@emory.edu}

Received 21 November 2007

Accepted 26 March 2008

\author{
Katy M. Clemmer ${ }^{1}$ and Philip N. Rather ${ }^{1,2}$ \\ ${ }^{1}$ Research Service, Veterans Affairs Medical Center, Decatur, GA, USA \\ ${ }^{2}$ Department of Microbiology and Immunology, Emory University School of Medicine, Atlanta, \\ GA, USA
}

\begin{abstract}
A mini-Tn5lacZ1 transposon insertion in a gene encoding an orthologue of the Lon protease conferred a hyper-swarming phenotype on Proteus mirabilis. The lon mutation increased the accumulation of mRNA for representative class 1 ( $f / h D C)$, class 2 ( fliA) and class $3(f / a A)$ genes during swarmer cell differentiation. In addition, the stability of the FlhD protein was fourfold higher in the lon : : mini-Tn5lacZ1 background. Expression of a single-copy lon : : lacZ fusion increased during the swarming cycle and reached peak levels of expression at a point just after swarmer cell differentiation had initiated. In liquid media, a condition normally non-permissive for swarming, the Ion : : mini-Tn5lacZ1 insertion resulted in motile, highly elongated cells that overexpressed flagellin. Finally, the lon: : mini-Tn5lacZ1 mutation was shown to result in increased expression of the $h p m B A$ and $z a p A$ virulence genes during swarmer cell differentiation.
\end{abstract}

\section{INTRODUCTION}

In Proteus mirabilis, the ability to swarm on agar surfaces requires vegetative cells to differentiate into elongated swarmer cells (Fraser \& Hughes, 1999; Rather, 2005). Swarmer cells assemble into multicellular rafts and migrate across surfaces (Jones et al., 2004). The differentiated swarmer cell represents a transient state and cells de-differentiate back to vegetative cells in a process termed consolidation. This represents one swarming cycle and the repeating cycle of differentiation and dedifferentiation results in the formation of characteristic rings that form a bulls-eye pattern on agar plates (Rauprich et al., 1996).

A central component in the regulation of swarmer cell differentiation in $P$. mirabilis is the class 1 FlhDC activator of the flagellar gene cascade (Furness et al., 1997). The $\mathrm{FlhD}_{2} \mathrm{C}_{2}$ heterotetrameric complex activates class 2 genes in the flagellar cascade, including fliA encoding $\sigma^{28}\left(\sigma^{\mathrm{F}}\right)$, which directs RNA polymerase to class 3 promoters, such as the flagellin $(f l a A)$ promoter (Claret \& Hughes, 2000a; Chilcott \& Hughes, 2000; Manos \& Belas, 2004). Artificial overexpression of FlhDC from an arabinose-inducible promoter results in a hyper-swarming phenotype (Furness et al., 1997; Hay et al., 1997). In P. mirabilis, the $f l h D C$ operon is negatively regulated by the RcsBCD phosphorelay (Clemmer \& Rather, 2007) and positively regulated by the Lrp and UmoB proteins (Hay et al., 1997; Dufour et al., 1998). In addition, $\mathrm{FlhD}_{2} \mathrm{C}_{2}$ activity is inhibited at the post-transcriptional level by an unknown mechanism that requires DisA, a putative phenylalanine decarboxylase (Stevenson \& Rather, 2006). The P. mirabilis
FlhD and FlhC proteins are also degraded by an energydependent protease in differentiated swarmer cells (Claret \& Hughes, 2000b). The protease responsible for this turnover was proposed to be the Lon protease based on increased stability in a heterologous Escherichia coli lon mutant (Claret \& Hughes, 2000b). However, prior to this study, the role of Lon in P. mirabilis on the stability of the native FlhD and FlhC proteins has not been addressed. In this study, we report the pleiotropic effects of a lon-null allele on swarming, flagellar gene expression and virulence gene expression.

\section{METHODS}

Bacterial strains, plasmids and growth conditions. All bacterial strains and plasmids used in this study are listed in Table 1. Medium for the growth of all strains was modified Luria-Bertani (LB) medium containing $10 \mathrm{~g}$ tryptone $\mathrm{l}^{-1}, 5 \mathrm{~g}$ yeast extract $\mathrm{l}^{-1}$ and $5 \mathrm{~g} \mathrm{NaCl} \mathrm{l}^{-1}$. Agar was added at a concentration of $1.5 \%$. Antibiotics were used at the following concentrations: streptomycin, $25 \mu \mathrm{g} \mathrm{ml}^{-1}$ for E. coli and $35 \mu \mathrm{g} \mathrm{ml}^{-1}$ for $P$. mirabilis; tetracycline, $25 \mu \mathrm{g} \mathrm{ml}^{-1}$ for E. coli and $P$. mirabilis; chloramphenicol, $25 \mu \mathrm{g} \mathrm{ml}^{-1}$ for E. coli and $100 \mu \mathrm{g} \mathrm{ml}^{-1}$ for P. mirabilis; and kanamycin, $35 \mu \mathrm{g} \mathrm{ml}^{-1}$ for P. mirabilis. DNA was introduced into $P$. mirabilis by electroporation as described previously (Rather et al., 1993).

Generation of a mini-Tn5lacZ1 insertional library. A conjugal mating was used to introduce random insertions of mini-Tn5lacZ1 into the P. mirabilis chromosome. Overnight cultures of E. coli SM10/ pUT:: mini-Tn5lacZ1 and P. mirabilis PM7002 were mixed together in $100 \mu \mathrm{l}$ aliquots, plated on an LB agar plate and grown for $6 \mathrm{~h}$ at $37{ }^{\circ} \mathrm{C}$. Cells were then scraped off the plate, resuspended in LB broth and plated on LB agar plates containing tetracycline $\left(15 \mu \mathrm{g} \mathrm{ml}^{-1}\right)$, kanamycin $\left(20 \mu \mathrm{g} \mathrm{ml}^{-1}\right)$ and X-Gal $(0.15 \%)$. 
Table 1. Bacterial strains and plasmids

\begin{tabular}{|c|c|c|}
\hline Strain/plasmid & Relevant phenotype & Source or reference \\
\hline \multicolumn{3}{|l|}{ Strains } \\
\hline \multicolumn{3}{|l|}{ E. coli } \\
\hline XL1-Blue & 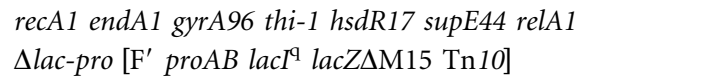 & Stratagene \\
\hline DH5 $\alpha$ & $\begin{array}{l}\text { recA1 endA1 gyrA96 thi-1 hsdR17 supE44 relA1 } \\
\Delta \text { lacZYA-argF U169 } \phi 80 \mathrm{~d} l a c Z \Delta \mathrm{M} 15\end{array}$ & Invitrogen \\
\hline SM10 $\lambda$ pir & thi thr leu tonA lacY supE recA RP4-2-Tc:: $\mathrm{Mu}, \mathrm{Km}^{\mathrm{R}}$ ipir & Miller \& Mekalanos (1988) \\
\hline \multicolumn{3}{|l|}{ P. mirabilis } \\
\hline PM7002 & Wild-type & ATCC \\
\hline PM2173 & 7002 lon: : mini-Tn5lacZ1 & This study \\
\hline PM2174 & PM2173 pPM-lon integrated at the lon region & This study \\
\hline \multicolumn{3}{|l|}{ Plasmids } \\
\hline pUT:: mini-Tn5lacZ1 & Transposon delivery vector & de Lorenzo et al. (1990) \\
\hline pKNG101 & R6K-derived suicide plasmid, $\mathrm{Sm}^{\mathrm{R}}$ & Kaniga et al. (1991) \\
\hline pBC.SK $(-)$ & High-copy-number vector, $\mathrm{Cm}^{\mathrm{R}}$ & Stratagene \\
\hline pACYC184 & Medium-copy-number vector, $\mathrm{Cm}^{\mathrm{R}} \mathrm{Tc}^{\mathrm{R}}$ & Chang \& Cohen (1978) \\
\hline pFDCH1 & pACYC184:: FLAG-FlhD + FlhC-His ${ }_{6}$ & This study \\
\hline pPM-lon & pKNG101::2.5 kb BamHI fragment containing lon & This study \\
\hline
\end{tabular}

Cloning procedures. The mini-Tn5lacZ1 insertion in PM2173 was not accompanied by a pUT co-integration as determined by Southern blot analysis and ampicillin sensitivity. The mini-Tn5lacZ1 insertion and flanking upstream DNA was isolated from PM2173 by digestion of chromosomal DNA and ligation of HindIII fragments into pACYC184 and selection for $\mathrm{lac}^{+}$XL1-Blue recombinants on X-Gal plates. The sequence of chromosomal DNA adjacent to the transposon insertion was determined using a primer $\left(5^{\prime}\right.$ CCAGATCTGATCAAGAGACAG-3') that read outward from the lacZ (I-end) end of mini-Tn5lacZ1. To create epitope-tagged versions of the FlhD and FlhC proteins, PCR $\left(30\right.$ cycles at $50{ }^{\circ} \mathrm{C}$ for annealing and $72{ }^{\circ} \mathrm{C}$ for extension) was used to amplify the $f l h D C$ operon from PM7002 using the following primers: FlhD amino FLAG, 5' CGATCGTCTAGATCGGACGGGATGTAAAGAGATGGATTATAAAGATGATGATGATAAAAGTACGGTTGAATTGCTTAAG-3'; and FlhC-His, 5' -ACATGTCGACTCAATGATGATGATGATGATGCATTGCAAACTGTTCAAGACC-3'. The epitope tags in each primer are underlined. These primers simultaneously generated a FLAG epitope tag at the N-terminus of FlhD and a $\mathrm{His}_{6}$ tag at the Cterminus of FlhC. This PCR-generated fragment also contained the native ribosome-binding site for $f l h D C$, but was missing its promoter. This fragment was cloned into pBC.SK(-) via $\mathrm{Xba \textrm {I }}$ and Sall sites incorporated into the PCR primers. This FLAG-FlhDFlhC-His ${ }_{6}$-containing insert was excised from pBC.SK and then cloned into pACYC184 as a PvuII-SalI fragment. This fragment also contained the lac promoter in the correct orientation to drive transcription of the tagged $f h D C$ genes.

To clone a wild-type copy of the lon gene, the following primers were used to amplify the lon gene and its native ribosome-binding site by PCR: 5'-GCTAGGATCCTACCTGTAAAAGCGTTAAGC-3' and 5'GCTAGGATCCTATTATGATTCACATCACG- ${ }^{\prime}$. This fragment was digested with BamHI and cloned into the BamHI site of pKNG101 (Kaniga et al., 1991) to generate pPM-lon. To integrate pPM-lon into the P. mirabilis chromosome as a single copy, E. coli SM10/ pPM-lon was subjected to a filter mating with PM2173 and exconjugants with pPM-lon integrated into the chromosome were selected on LB plates containing streptomycin $\left(35 \mu \mathrm{g} \mathrm{ml}^{-1}\right)$ and tetracycline $\left(15 \mu \mathrm{g} \mathrm{ml}^{-1}\right)$.
Northern blot analysis. Expression of flhDC, fliA, flaA, hmpA and zapA during the swarmer cell differentiation cycle was measured by Northern blot analysis of total RNA. Cells were harvested for RNA analysis by plating $150 \mu \mathrm{l}$ of overnight cultures of PM7002 and PM2173 at an $\mathrm{OD}_{600}$ of 1.5 on individual LB agar plates, followed by isolation of cells from plates at hourly intervals. RNA was extracted using a MasterPure RNA Purification kit (Epicentre) following the standard protocol with the addition of a 20 min DNase treatment. Formamide/formaldehyde-denatured RNA was resolved by electrophoresis through a $1.2 \%$ agarose/formaldehyde gel and transferred onto nitrocellulose membranes by capillary transfer. Blots were probed with digoxigenin-labelled PCR products corresponding to each gene, which were generated with the following primers: flaA, $5^{\prime}$ TATCTGGGGTGCCGATAAAC-3' and 5' -ACGGTTTTGAATCGCACCTA-3'; flhDC, 5'-TCGGACGGGATGTAAAGAGA-3' and 5'-CAGGATTGGCGGAAAGTTTA-3'; fliA, 5' -TAGCCTCTGGGAGCGATATG-3' and 5'-GCACTGCGCCTATTTCTTTC- ${ }^{\prime}$; ' ${ }^{\prime} p m A, 5^{\prime}$ CAAAAACCCGTTTCAGCATT-3' and $5^{\prime}$-TTGTTACCCGGTTTGGTTGT-3'; and zapA, 5'-CCCGCTGAGGTGACTTATTC-3' and 5'TGGCTAATTCAGAAGCATTGG-3'.

Western blot analysis. FlaA protein levels were assessed in whole-cell lysates of $P$. mirabilis strains using Western blot analysis. Cells were grown overnight without shaking at $37{ }^{\circ} \mathrm{C}$ to an $\mathrm{OD}_{600}$ of 0.5 . One millilitre of cells was pelleted and lysed in Laemmli sample buffer by heating at $95{ }^{\circ} \mathrm{C}$ for $10 \mathrm{~min}$. Protein samples were separated by SDSPAGE using a Bio-Rad ReadyGel system and $15 \%$ Tris/HCl gels. Identical amounts of protein were loaded for each sample based on prequantification on SDS-PAGE gels, followed by Coomassie blue staining. Total protein was electrotransferred to nitrocellulose and probed with rabbit antibodies to $P$. mirabilis FlaA (kindly provided by Robert Belas, Center of Marine Biotechnology, University of Maryland, MD, USA) at a 1:40000 dilution, followed by incubation with a horseradish peroxidase-conjugated anti-rabbit antibody (Amersham Biosciences) at a 1:35000 dilution. Detection was carried out using ECL Western Blotting Detection Reagents in accordance with standard procedures (Amersham Biosciences). Detection of FLAG-tagged and His $_{6}$-tagged proteins was done by Western blot analysis as described above using an anti-FLAG (Sigma) or anti-His ${ }_{6}$ (Qiagen) antibody. 


\section{RESULTS}

\section{A lon : : mini-Tn5lacZ1 insertion increases swarming motility}

Approximately 80000 mini-Tn5lacZ1 insertions were screened visually after $12 \mathrm{~h}$ growth on LB agar plates for colonies with an enhanced swarming phenotype. One mutant with this phenotype contained mini-Tn5lacZ1 inserted in an ORF that encoded a product with $90 \%$ identity to a Lon homologue from Photorhabdus luminescens and $89 \%$ identity to Lon from Yersinia pestis. The insertion disrupted this ORF at a position corresponding to aa 219 of the predicted 784 aa protein. Based on the genome sequence of HI4320 (http://www.sanger.ac.uk/ Projects/P_mirabilis), the DNA upstream of the putative lon gene encoded an ORF that directed a product with $88 \%$ amino acid identity to the ClpX protease subunit, and downstream of lon was a putative $h u p B$ gene, encoding a product with $81 \%$ amino acid identity to the histone-like $\mathrm{Hu}-1$ protein of E. coli. Therefore, the genetic organization of the region surrounding the $P$. mirabilis lon gene was identical to that seen in E. coli. In P. mirabilis, the hupB gene was separated by $210 \mathrm{nt}$ from the $3^{\prime}$ end of the lon coding region; therefore, the insertion in lon was not likely to be polar on $h u p B$.

Swarming migration of the PM2173 lon::mini-Tn5lacZ1 mutant was compared with that of the wild-type PM7002.
Swarming was initiated at the same time as the wild-type; however, the migration rate of the lon mutant was $50 \%$ greater by the first consolidation period (Fig. 1a). At the end of $8 \mathrm{~h}$ of migration, the lon mutant had translocated $8.1 \mathrm{~cm}$ compared with $4.7 \mathrm{~cm}$ for the wild-type PM7002 cells.

Based on previous work demonstrating that a lon mutation in Vibrio parahaemolyticus resulted in constitutive swarmer cell differentiation in liquid medium (Stewart et al., 1997), normally a non-permissive condition, we examined the morphology of PM2173 lon::mini-Tn5lacZ1 in liquid medium. In contrast to wild-type PM7002, which contained undifferentiated cells, the culture of PM2173 contained cells that were highly elongated and very motile (Fig. 1b) and appeared identical to swarmer cells harvested from plates. The elongated cells (greater than $10 \mu \mathrm{m})$ represented $15.6 \%(20 / 128)$ of the total cell population in the PM2173 culture. One characteristic of a differentiated swarmer cell is the increased expression of flagellin (Belas, 1994). To obtain further evidence that the elongated cells observed in liquid cultures of the lon mutant were differentiated swarmer cells, the levels of flagellin were assayed in wild-type PM7002 and the PM2173 lon::mini-Tn5lacZ1 mutant in cells grown in liquid and harvested at mid-exponential phase $\left(\mathrm{OD}_{600}=0.6\right)$. The overall levels of flagellin for the pooled cells were threefold higher in PM2173 cells than in wild-type PM7002 (Fig. 1c). It is important to note that, (a)

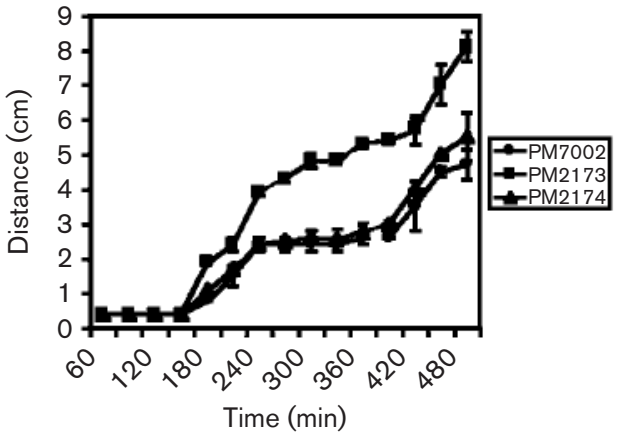

(b)

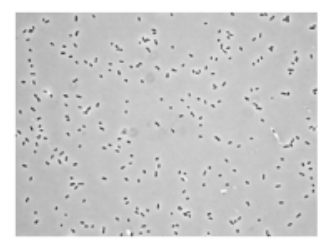

PM7002

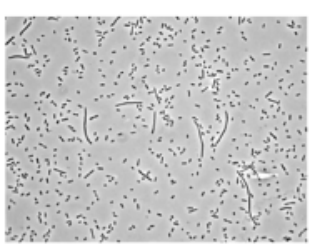

PM2173

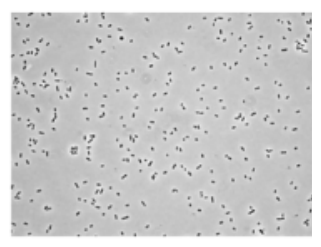

PM2174 (c)

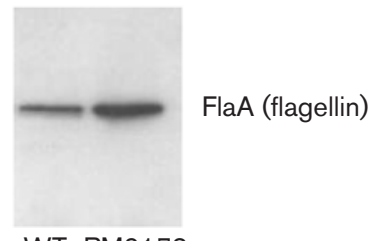

WT PM2173
Fig. 1. Effect of the lon::mini-Tn5/acZ1 mutation on swarming. (a) Swarming assays. Cultures of PM7002, PM2173 lon::miniTn5lacZ1 and PM2174 lon::mini-Tn5/acZ1, $\phi$ pPM-lon were grown to saturation in LB medium or LB medium containing $35 \mu \mathrm{g}$ streptomycin $\mathrm{ml}^{-1}$ (for PM2174) with shaking at $37{ }^{\circ} \mathrm{C}$. Cells from each tube were adjusted to an $\mathrm{OD}_{600}$ of 1.5 and duplicate $1 \mu$ spots for each strain were applied to the surface of a fresh LB agar ( $1.5 \%)$ plate without antibiotics. Plates were incubated at $37^{\circ} \mathrm{C}$ and migration was measured at $30 \mathrm{~min}$ intervals. The reported values represent the means \pm SD of duplicate samples for each strain. (b) The cell morphology of the liquid cultures at an $\mathrm{OD}_{600}$ of 0.6 was examined by phase-contrast microscopy. (c) Cells were pelleted at an $\mathrm{OD}_{600}$ of 0.6 for analysis of flagellin (FlaA) expression by Western blot analysis using an anti-FlaA antibody. Identical amounts of protein from cell lysates were loaded in each lane. 
as this experiment was done with pooled cells and elongated cells only represented $15.6 \%$ of the total cell population, the actual increase in flagellin expression in each individual swarmer cell is likely to be much higher. Therefore, in P. mirabilis, as in V. parahaemolyticus, loss of the Lon protease allowed swarmer cell differentiation under non-permissive conditions.

To verify that the swarming and cell-elongation phenotypes were due to the lon mutation, we introduced pPMlon, containing the cloned wild-type lon gene, back into PM2173. In PM2173/pPM-lon cells (PM2174), the levels of swarming were reduced to wild-type levels (Fig. 1a). For the phenotype of cell elongation in liquid, the presence of pPM-lon also fully complemented the lon mutation (Fig. 1b).

\section{Increased expression of genes in the flagellar cascade in a lon mutant background}

To examine the possible basis for the hyper-swarming phenotype of the lon::mini-Tn5lacZ1 mutant, the expression of representative class 1, 2 and 3 genes in the flagellar cascade was examined by Northern blot analysis (Fig. 2). Cells were harvested for RNA analysis by plating $150 \mu \mathrm{l}$ of overnight cultures of PM7002 and PM2173 at an $\mathrm{OD}_{600}$ of 1.5 on individual LB agar plates, followed by isolation of cells from the plates at hourly intervals $\left(T_{3}\right.$ indicates $3 \mathrm{~h}$ after plating). The accumulation of mRNA for the class 1 master regulator flhDC at $T_{3}$, when swarmer cell differentiation began, was similar in the wild-type PM7002 and PM2173 lon::mini-Tn5lacZ1 backgrounds and then declined significantly at $T_{4}$ and $T_{5}$ in wild-type cells. In contrast, the decrease in flhDC mRNA at $T_{4}$ and $T_{5}$ was not observed in the PM2173 mutant. The FlhDCdependent class 2 gene fliA $\left(\sigma^{28}\right)$ and the fliA-dependent class $3 \mathrm{flaA}$ gene also exhibited significantly enhanced mRNA accumulation at $T_{4}$ and $T_{5}$ in the lon::miniTn5lacZ1 background, when compared with wild-type (Fig. 2).

\section{FIhD accumulates to higher levels in a Ion mutant}

Previous studies have indicated that both FlhD and FlhC are rapidly degraded in swarmer cells by an energydependent protease (Claret \& Hughes, 2000b). To examine the possible role of Lon in the proteolysis of FlhD and FlhC, a FLAG epitope tag (DYKDDDDK) was placed at the $\mathrm{N}$-terminus of FlhD and a $\mathrm{His}_{6}$ tag at the C-terminus of FlhC by PCR (see Methods) and antibodies to the respective tags were used to monitor protein accumulation. In addition, as the results in Fig. 2 indicated that transcription of $f l h D C$ was increased in the lon mutant, the tagged FlhDC proteins were expressed from a heterologous promoter (E. coli lac) that is not FlhDC regulated to uncouple transcription from the native promoter and allow changes in protein accumulation to be monitored independently of transcription. P. mirabilis

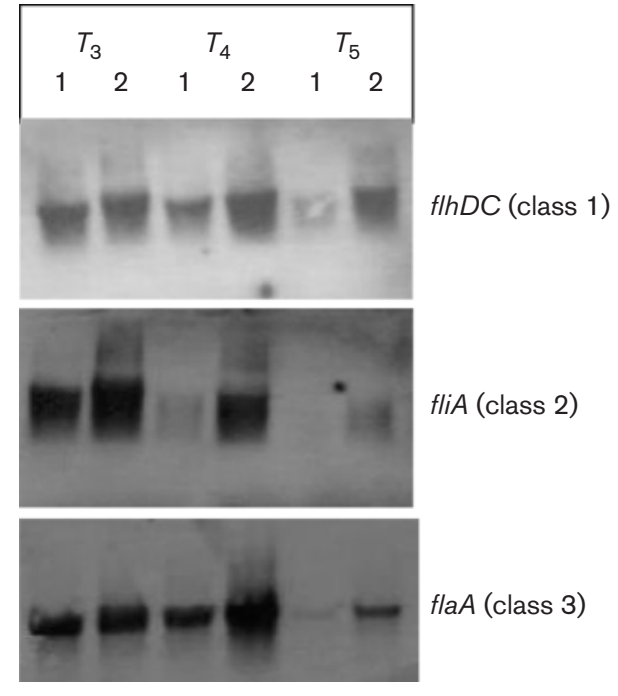

Fig. 2. Effect of the lon mutation on flagellar gene expression. PM7002 and PM2173 were grown to saturation by shaking overnight at $37{ }^{\circ} \mathrm{C}$ in LB broth, adjusted to the same optical density and $100 \mu \mathrm{l}$ aliquots were plated on LB agar plates to generate synchronously differentiating cells. At hourly intervals, cells were harvested from the plates by resuspending in cold LB broth and RNA was prepared from cells at each time point for Northern blot analysis using the indicated probes. Each lane contained $10 \mu \mathrm{g}$ RNA and all samples were standardized to the same concentration before loading. For all time points, lane 1 represents wild-type PM7002 samples and lane 2 represents samples from PM2173 lon : : mini-Tn5lacZ1.

PM7002 containing plasmid pFDCH1 with the tagged FlhDC proteins exhibited a hyper-swarming phenotype, indicating that the FLAG-FlhD and FlhC-His $_{6}$ proteins retained biological function (data not shown). The levels of FLAG-FlhD and FlhC-His ${ }_{6}$ proteins were examined in wild-type PM7002 and PM2173 lon::mini-Tn5lacZ1 by Western blot analysis using anti-FLAG and anti-His antibodies. For these experiments (Fig. 3), cells were harvested from plates at $T_{4}$, a time point where maximal expression of lon was observed based on lac $Z$ fusion analysis (see Fig. 5). The levels of FlhD were clearly higher in the PM2173 lon:: mini-Tn5lacZ1 background relative to wild-type PM7002 (Fig. 3). However, the level of the FlhC protein was similar in both PM2173 and wild-type PM7002. The half-life of FlhD was determined in both the wild-type and lon mutant backgrounds (data not shown). The half-life for FlhD was $8 \mathrm{~min}$ in the wild-type background and $32 \mathrm{~min}$ in the lon mutant background. For the FlhC protein, there was no difference in the wild-type or lon mutant backgrounds at $32 \mathrm{~min}$ and the levels were unchanged at this time point relative to the cells before inhibition of protein synthesis (data not shown). Therefore, FlhD is much less stable than FlhC and this instability is largely due to degradation by Lon. 

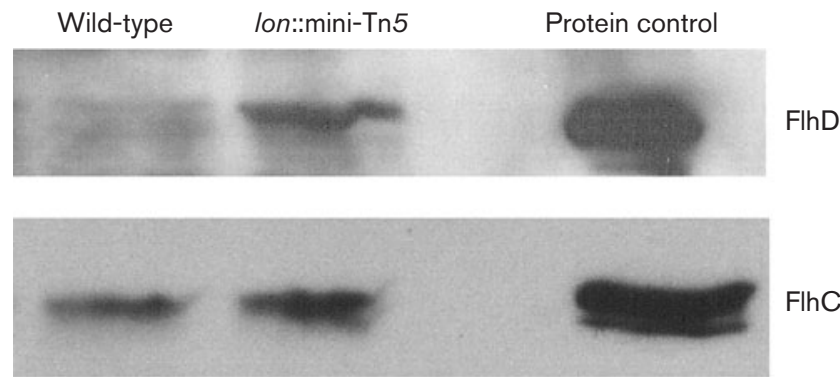

Fig. 3. Accumulation of $\mathrm{FlhD}$ and FlhC proteins in the lon mutant background. Overnight cultures of PM7002/pFDCH1 and $\mathrm{PM} 2173 / \mathrm{pFDCH} 1$ were adjusted to an $\mathrm{OD}_{600}$ of 1.6 and $150 \mu \mathrm{l}$ aliquots were spread on LB agar plates containing chloramphenicol at $100 \mu \mathrm{g} \mathrm{ml}^{-1}$. Cells were harvested $4 \mathrm{~h}$ after plating $\left(T_{4}\right)$ by resuspending in cold LB broth and pelleted. The samples were adjusted to the same protein concentration, which was confirmed by Coomassie staining. Samples were separated by $15 \%$ SDS-PAGE and subjected to Western blot analysis using anti-FLAG (Sigma) or anti-His (Qiagen) antibody.

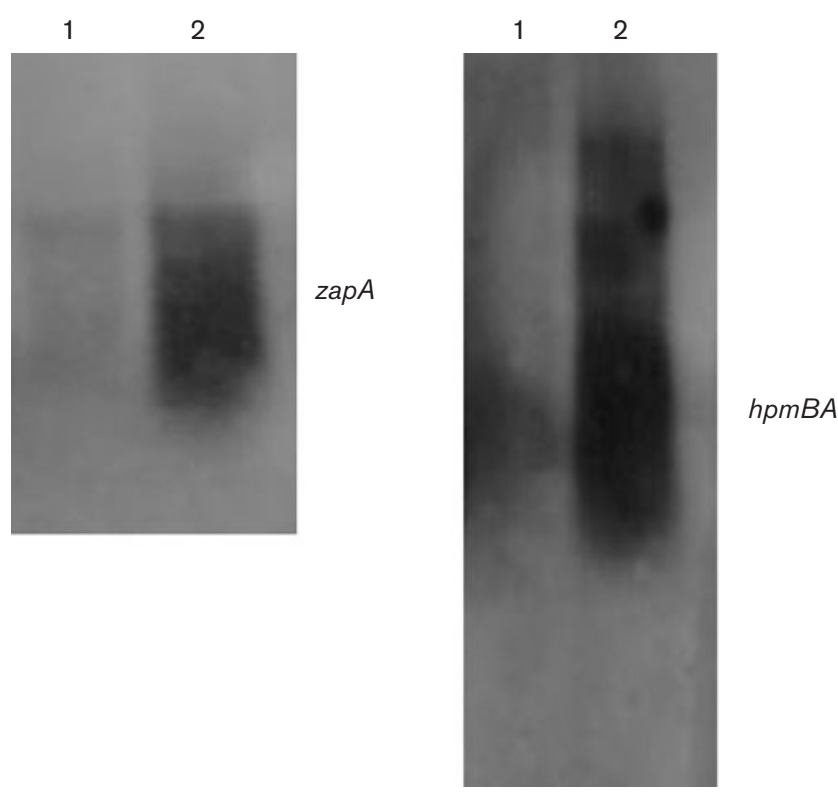

Fig. 4. Accumulation of zap and hpm mRNA. RNA was prepared from synchronously differentiating cells of wild-type PM7002 and PM2173 Ion::mini-Tn5lacZ1 harvested at $T_{6}$. Northern blot analysis was carried out with probes to the zapA and hpmA genes that were generated by PCR. Each lane represents $10 \mu \mathrm{g}$ RNA and all samples were standardized to the same concentration before loading. Lane 1 represents wild-type PM7002 samples and lane 2 represents samples from the PM2173 lon : : mini-Tn5lacZ1 mutant.

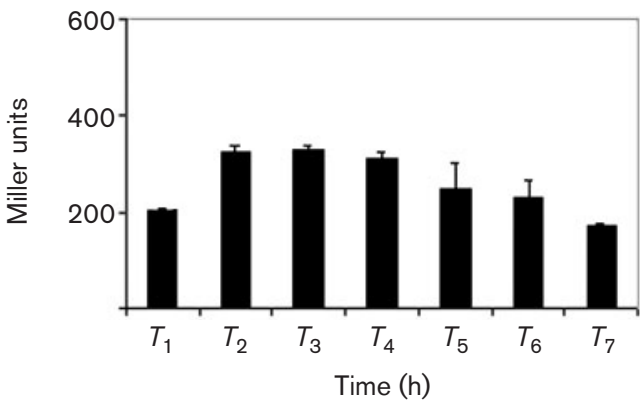

Fig. 5. Expression of a lon : lacZ fusion during swarming. An overnight stationary-phase culture of PM2173 was used to inoculate a series of LB plates $(100 \mu \mathrm{l}$ per plate). At hourly intervals, cells were harvested from a single plate and resuspended in cold LB broth and adjusted to an $\mathrm{OD}_{600}$ of 1.0 . Cells were pelleted in duplicate $(0.9 \mathrm{ml})$ and assayed for $\beta$-galactosidase using the method of Miller (1972). The values shown represent duplicate samples from one experiment. Repeated experiments gave similar results to those shown.

\section{Increased virulence gene expression in the lon mutant background}

The expression of two virulence genes, zapA encoding an IgA metalloprotease and $h p m B A$ encoding a haemolysin, was examined in fully differentiated swarmer cells (at $T_{6}$ ) of the wild-type and lon mutant by Northern blot analysis (Fig. 4). For both transcripts, the levels of expression were at least fivefold higher in the lon mutant background when compared with wild-type.

\section{Lon expression increases in differentiated swarmer cells}

In the lon mutant, there was minimal difference in flagellar gene expression in cells that were in the early stages of differentiation (Fig. 2; $T_{3}$ time point), but a larger change was seen in cells that had already differentiated (Fig. 2; $T_{5}$ time point). This indicated that Lon expression might be increased at $T_{5}$ and could contribute to the decrease in flagellar gene expression at this point in swarming. To examine this possibility, we took advantage of the fact that the lon::mini-Tn5lacZ1 insertion was in the correct orientation to create a single-copy lon:: lac $Z$ fusion. Expression of the lon: : lac $Z$ fusion was measured at hourly intervals in synchronously differentiating cells of $P$. mirabilis. Peak levels of lon: :lacZ expression were observed in cells from $T_{2}$ to $T_{3}$, when swarmer cell differentiation had just initiated (Fig. 5). At these time points, the levels of expression were modestly increased (60\% higher) from that at $T_{1}$. At time points when cells began to de-differentiate back to vegetative cells $\left(T_{7}\right)$, the levels of lon:: lacZ expression dropped back to preswarming levels. 


\section{DISCUSSION}

A transposon insertion within the Lon orthologue of $P$. mirabilis was identified based on the resulting hyperswarming phenotype (Fig. 1). The basis for this phenotype was twofold. First, in the lon mutant background, there were higher levels of flhDC expression during swarmer cell differentiation. This allowed cells to maintain higher levels of flagellin expression at $T_{4}$ and $T_{5}$, a point when this would normally start to decrease (Fig. 2). Since $\mathrm{FlhD}_{2} \mathrm{C}_{2}$ also has an important role in swarmer cell differentiation (Furness et al., 1997), the prolonged expression of flhDC and possibly fliA $\left(\sigma^{28}\right)$ maintains the expression of genes required for swarmer cell differentiation for longer than normal periods. Secondly, FlhD was present in higher amounts (Fig. 3) and had a significantly longer half-life in the lon mutant background. Previous studies examining the stability of $P$. mirabilis FlhD and FlhC in a heterologous E. coli host have revealed a role for the Lon protease in the degradation of both proteins (Claret \& Hughes, 2000b). However, our data indicated that FlhD is the primary substrate of Lon in the native $P$. mirabilis host.

The prolonged flhDC mRNA accumulation during swarming in a lon mutant background was unexpected. However, as FlhD was stabilized in the lon mutant, the increase in flhDC mRNA accumulation may be due to a positive feedback mechanism from a downstream gene product that is dependent on FlhDC for expression. One candidate for this gene product is fliA $\left(\sigma^{28}\right)$, whose expression is FlhDCdependent. Previous studies in E. coli have shown that RNA polymerase containing FliA can transcribe the flhDC promoter in a positive feedback loop (Clarke \& Sperandio, 2005). Similar studies in P. mirabilis have not been reported and the role of FliA in a feedback loop is speculative at this time. A second possibility is that another activator of $f l h D C$ is a substrate of Lon and accumulates in a lon mutant background, leading to prolonged flhDC expression. One candidate for this regulator is the leucineresponsive regulatory protein (Lrp), an activator of $f l h D C$ during swarmer cell differentiation (Hay et al., 1997). Lrp is also required for activation of the hpmAB operon (Fraser et al., 2002) and the potentially increased levels of Lrp in the lon mutant during swarmer cell differentiation may explain the higher levels of $h m p$ expression at this time (Fig. 4). A second regulatory protein that may be degraded by Lon is $U m o B$, a protein of unknown function that is required for the expression of both flhDC and $h m p B A$ (Dufour et al., 1998; Fraser et al., 2002). Further studies will be aimed at determining whether Lrp, UmoB or other proteins are additional substrates of the Lon protease.

\section{ACKNOWLEDGEMENTS}

We are grateful to Robert Belas for providing the FlaA antibody. This work was supported by a Merit Review Award from the Department of Veterans Affairs. P.N.R. is the recipient of a Research Career Development Award from the Department of Veterans Affairs.

\section{REFERENCES}

Belas, R. (1994). Expression of multiple flagellin-encoding genes of Proteus mirabilis. J Bacteriol 176, 7169-7181.

Chang, A. C. \& Cohen, S. N. (1978). Construction and characterization of amplifiable DNA cloning vehicles derived from the p15A cryptic miniplasmid. J Bacteriol 134, 1141-1156.

Chilcott, G. S. \& Hughes, K. T. (2000). Coupling of flagellar gene expression to flagellar assembly in Salmonella enterica serovar typhimurium and Escherichia coli. Microbiol Mol Biol Rev 64, 694-708.

Claret, L. \& Hughes, C. (2000a). Functions of the subunits of the $\mathrm{FlhD}_{2} \mathrm{C}_{2}$ transcriptional master regulator of bacterial flagellum biogenesis and swarming. J Mol Biol 303, 467-478.

Claret, L. \& Hughes, C. (2000b). Rapid turnover of FlhD and FlhC, the flagellar regulon transcriptional activator proteins, during Proteus swarming. J Bacteriol 182, 833-836.

Clarke, M. B. \& Sperandio, V. (2005). Transcriptional regulation of flhDC by QseBC and $\sigma^{28}$ (FliA) in enterohemorrhagic E. coli. Mol Microbiol 57, 1734-1749.

Clemmer, K. M. \& Rather, P. N. (2007). Regulation of FlhDC expression in Proteus mirabilis. Res Microbiol 158, 295-302.

de Lorenzo, V., Herrero, M., Jakubzik, U. \& Timmis, K. N. (1990). Mini-Tn5 derivatives for insertion mutagenesis, promoter probing, and chromosomal insertion of cloned DNA in gram-negative eubacteria. J Bacteriol 172, 6568-6572.

Dufour, A., Furness, R. B. \& Hughes, C. (1998). Novel genes that upregulate the Proteus mirabilis flhDC master operon controlling flagellar biogenesis and swarming. Mol Microbiol 29, 741-751.

Fraser, G. M. \& Hughes, C. (1999). Swarming motility. Curr Opin Microbiol 2, 630-635.

Fraser, G. M., Claret, L., Furness, R., Gupta, S. \& Hughes, C. (2002). Swarming-coupled expression of the Proteus mirabilis hpmBA haemolysin operon. Microbiology 148, 2191-2201.

Furness, R. B., Fraser, G. M., Hay, N. A. \& Hughes, C. (1997). Negative feedback from a Proteus class II flagellum export defect to the flhDC master operon controlling cell division and flagellum assembly. J Bacteriol 179, 5585-5588.

Hay, N. A., Tipper, D. J., Gygi, D. \& Hughes, C. (1997). A nonswarming mutant of Proteus mirabilis lacks the Lrp global transcriptional regulator. J Bacteriol 179, 4741-4746.

Jones, B. V., Young, R., Mahenthiralingam, E. \& Stickler, D. J. (2004). Ultrastructure of Proteus mirabilis swarmer cell rafts and role of swarming in catheter-associated urinary tract infection. Infect Immun 72, 3941-3950.

Kaniga, K., Delor, I. \& Cornelis, G. R. (1991). A wide-host-range suicide vector for improving reverse genetics in Gram-negative bacteria: inactivation of the blaA gene of Yersinia enterocolitica. Gene 109, 137-141.

Manos, J. \& Belas, R. (2004). Transcription of Proteus mirabilis flaAB. Microbiology 150, 2857-2863.

Miller, J. H. (1972). Experiments in Molecular Genetics. Cold Spring Harbor, NY: Cold Spring Harbor Laboratory.

Miller, V. L. \& Mekalanos, J. J. (1988). A novel suicide vector and its use in construction of insertion mutations: osmoregulation of outer membrane proteins and virulence determinants in Vibrio cholerae requires toxR. J Bacteriol 170, 2575-2583.

Rather, P. N. (2005). Swarmer cell differentiation in Proteus mirabilis. Environ Microbiol 7, 1065-1073. 
Rather, P. N., Orosz, E., Shaw, K. J., Hare, R. \& Miller, G. (1993). Characterization and transcriptional regulation of the $2^{\prime}-N$-acetyltransferase gene of Providencia stuartii. J Bacteriol 175, 6492-6498.

Rauprich, O., Matsushita, M., Weijer, C. J., Siegert, F., Esipov, S. E. \& Shapiro, J. A. (1996). Periodic phenomena in Proteus mirabilis swarm colony development. J Bacteriol 178, 6525-6538.
Stevenson, L. G. \& Rather, P. N. (2006). A novel gene involved in regulating the flagellar gene cascade in Proteus mirabilis. J Bacteriol 188, 7830-7839.

Stewart, B. J., Enos-Berlage, J. L. \& McCarter, L. L. (1997). The lonS gene regulates swarmer cell differentiation of Vibrio parahaemolyticus. J Bacteriol 179, 107-114. 